\title{
Pseudoangiomatous Stromal Hyperplasia-Case Report of a Rare Breast Tumor in a Premenarchal Girl
}

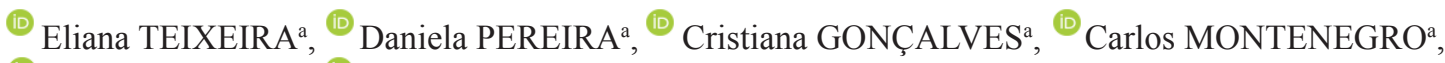 \\ (D) Carlos FIRMINOa, ${ }^{\text {D }}$ Lurdes RAMALHO \\ aDepartment of Gynecology and Obstetrics, Centro Hospitalar Barreiro Montijo, Barreiro, PORTUGAL
}

\begin{abstract}
Pseudoangiomatous stromal hyperplasia is a rare benign breast neoplasm. The exact prevalence of this condition is unknown. According to the literature, it is an extremely uncommon disease in adolescent patients, especially when presenting with a giant mass causing significant breast enlargement. The clinical management of pseudoangiomatous stromal hyperplasia continues to be a controversial issue, however, surgical treatment remains the most accepted when there is an important mass-effect. We report the case of a 12-year-old premenarchal female, referred to our hospital with complaints of a rapidly enlarging left breast mass, of $12 \mathrm{~cm}$ in diameter, causing a significant breast asymmetry. The ultrasonographic findings were unspecific. The core needle biopsy of the mass was consistent with pseudoangiomatous stromal hyperplasia, consequently, successful surgical excision was performed. This case illustrates a particularly unusual presentation of pseudoangiomatous stromal hyperplasia in a premenarchal adolescent patient, that should be taken into consideration in the differential diagnosis of abrupt breast enlargement.
\end{abstract}

Keywords: Pseudoangiomatous stromal hyperplasia; breast neoplasm; adolescent; case report

Pseudoangiomatous stromal hyperplasia (PASH) represents a rare non-cancerous neoplasm of the breast, defined as an exaggerated proliferation of fibrous stroma, containing slit-like pseudovascular channels coated with myofibroblasts. The pattern of incidence, mainly in reproductive age women, supports the hormonal etiology that has been postulated. PASH is exceedingly rare in young adolescent girls..$^{1-3}$ The lack of true vessels and absence of cytological pleomorphism are the specific distinctive features in the differential diagnosis with low-grade angiosarcoma. ${ }^{4,5}$ In addition, due to the radiological and clinical appearance of $\mathrm{PASH}$, the differential diagnosis includes fibroadenoma, mostly in youngsters, as well as phyllodes tumor in elder patients.

PASH has a wide spectrum of clinical presentations: often is recognized as a microscopic abnormal pattern identified incidentally; occasionally, a breast lump is perceived in the clinical evaluation and, on rare occasions, it presents with a giant mass causing asymmetry of the breast, referred as nodular or massforming PASH type. ${ }^{4,6}$

\section{CASE REPORT}

A 12-year-old black girl, was referred to our hospital by her family physician with complaints of a rapidly enlarging left breast mass, growing during the last 12 months, causing significant breast asymmetry (Figure 1). Her medical records were remarkable only for type 1 diabetes since she was 8 -years-old and she had no family history of benign breast lesions or breast and ovarian cancer. The patient was premenarchal and was not under hormonal contraception or other medication besides insulin injections.

Physical examination revealed a solid lump of about $12 \mathrm{~cm}$ in diameter, with well-circumscribed borders, on the outer quadrants of her left breast.

Correspondence: Eliana TEIXEIRA

Department of Gynecology and Obstetrics, Centro Hospitalar Barreiro Montijo, Barreiro, PORTUGAL

E-mail: eliana_teixeira_581@hotmail.com

Peer review under responsibility of Journal of Clinical Obstetrics \& Gynecology.

Received: 07 Oct 2020

Accepted: 11 Nov 2020

Available online: 24 Dec 2020

2619-9467 / Copyright (C) 2020 by Türkiye Klinikleri. This is an open

access article under the CC BY-NC-ND license (http://creativecommons.org/licenses/by-nc-nd/4.0/). 


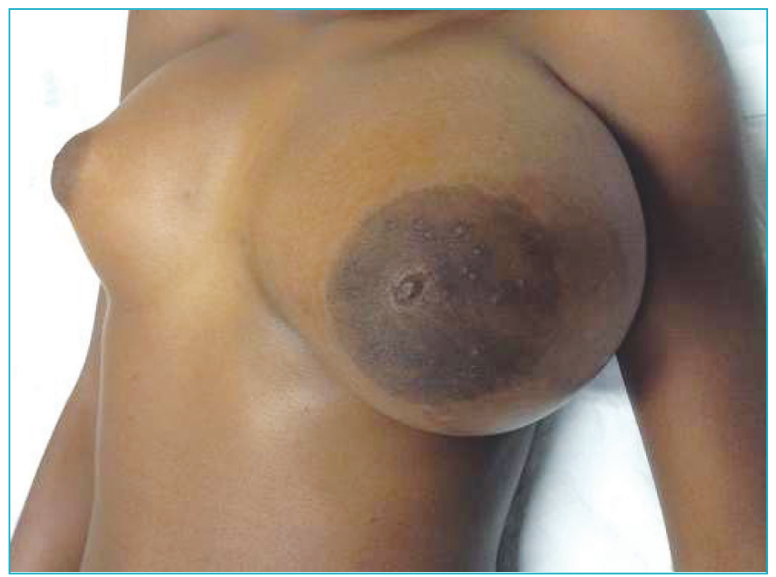

FIGURE 1: Preoperative view of the patient showing enlargement of the left breast causing significant asymmetry.

The axillary lymph nodes were not palpable and there was no evidence of skin or nipple retraction.

The ultrasound evaluation demonstrated a solid hypoechoic nodule of $11 \times 10 \mathrm{~cm}$ in diameter, with well-defined margins, resembling a giant fibroadenoma or phyllodes tumor. Hence, a core needle biopsy of the nodule was performed (Figure 2). The histopathologic study showed dense collagenous proliferation with slit-like channels resembling vascular areas coated with spindle-shaped myofibroblasts and widespread membranous immuno- reactivity to CD34, aspects compatible with PASH (Figure 3).

Considering the age of the patient, along with the dimensions of the lesion, a multidisciplinary group endorsed surgical excision. The technical approach was through an inframammary incision, excising an oval mass with $13 \mathrm{~cm}$ in diameter (Figure 4, Figure 5). The postoperative period was unre-

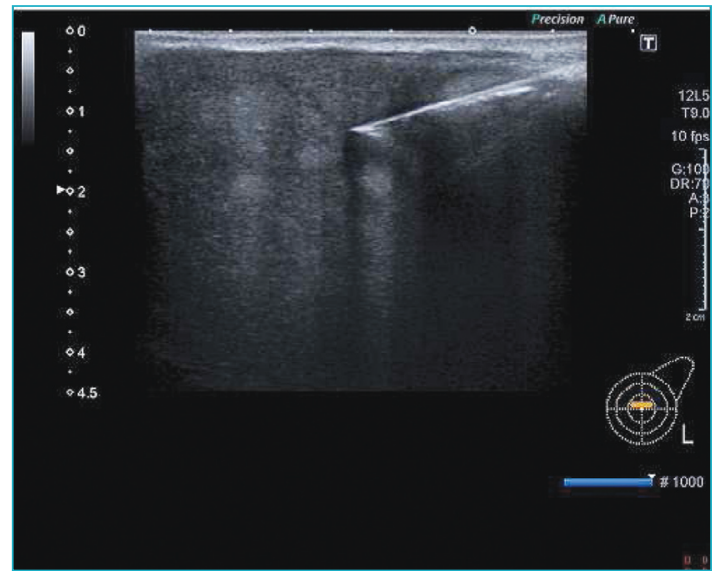

FIGURE 2: Ultrasound image of the core needle biopsy of the hypoechoic and well-defined breast mass.

markable and the histopathologic analysis confirmed the diagnosis of PASH.

At 3-year follow-up, the patient remained asymptomatic, without clinical or radiologic evidence of recurrence and with excellent cosmetic results (Figure 6, Figure 7). The informed consent was attached to the files at submission.

\section{DISCUSSION}

Pseudoangiomatous stromal hyperplasia was recognized originally by Vuitch and colleagues in 1986, however the etiology and pathophysiology of this rare disease persist unclear. ${ }^{7}$ A hormone-dependent stromal change has been the most acknowledged theory. ${ }^{1,5,8}$ This is supported by the high prevalence of premenopausal women among patients suffering from PASH, in spite of that, there are sparce cases of the disease described in postmenopausal women and
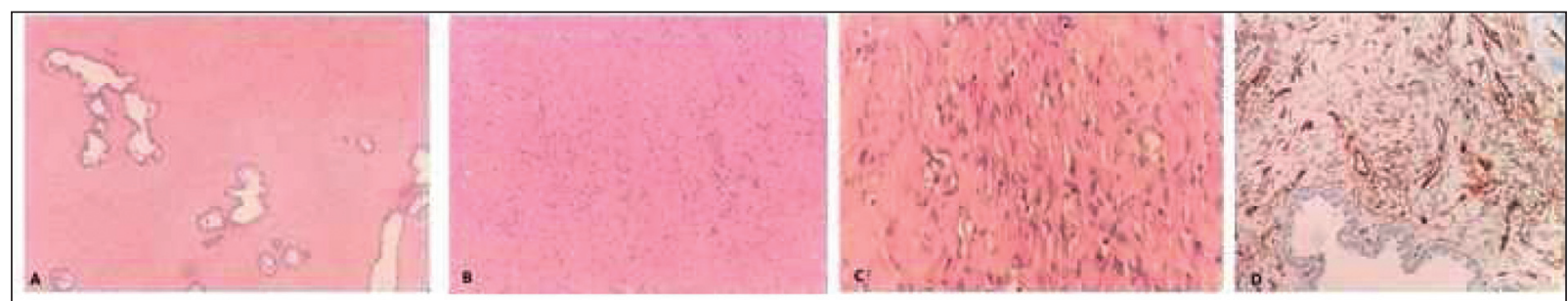

FIGURE 3: Microscopic view of the mass. (A and B) Hematoxylin and eosin stain (H\&E), low magnification (10x), stromal proliferation, hypercellular, with slite-like pseudovascular spaces; (C) H\&E, with high magnification (40x), is possible to observe a dense collagenous proliferation with slit-like pseudovascular spaces lined by spindleshaped cells, without cytological atypia or mitotic activity; (D) The immunohistochemical study with CD34 shows membranous and diffuse immunoreactivity, characteristic of PASH (20x). 


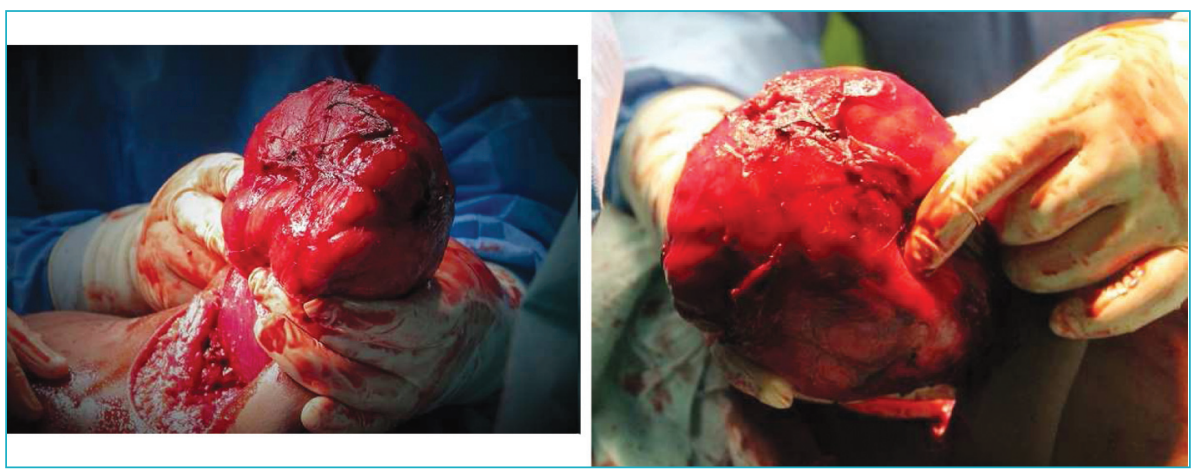

FIGURE 4-5: Macroscopic appearance of the breast tumor during surgical excision.

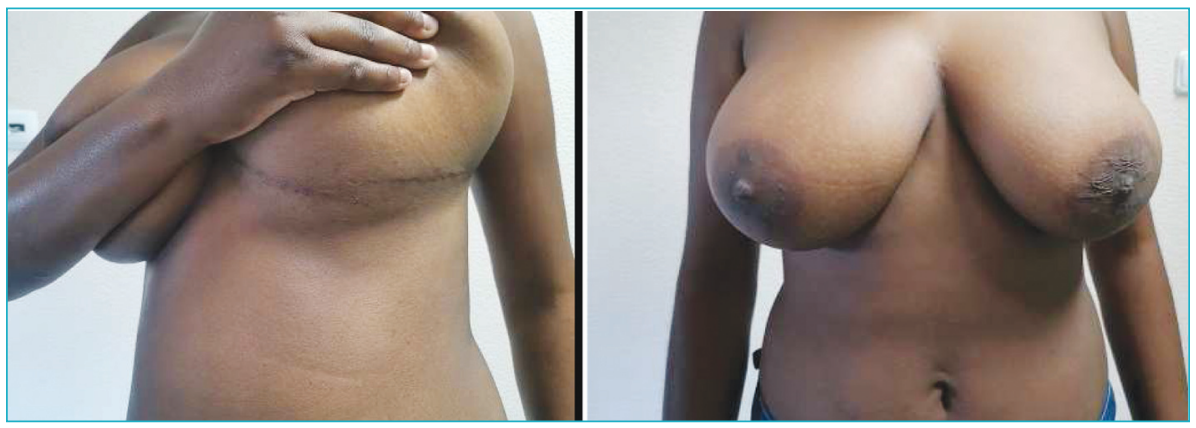

FIGURE 6-7: Clinical and cosmetic appearance at 3-year follow-up, the patient had significant body mass index increase, however there is no breast asymmetry after surgery.

adolescents, as in the case we report. Nonetheless, the literature reports that most of the PASH tumors disclosed in postmenopausal women were in patients under hormone replacement therapy. ${ }^{1}$ Progesterone receptors expressed on the nuclei of myofibroblasts in PASH cases, encourages the role of hormonal influence in its pathogenesis, as well. ${ }^{9}$

Clinically, PASH can be mistaken for fibroadenoma, as a result of its nonspecific presentation and sonographic appearance. ${ }^{3}$ Frequently, PASH is visualized as an elliptical hypoechogenic mass, with wellcircumscribed borders, resembling fibroadenoma. Thus, histopathologic analysis is the key element for an accurate diagnosis of this condition.

On histologic examination, the presence of spindle-shaped cells may be misinterpreted for other breast diseases, such as phyllodes tumor. Notwithstanding, low-grade angiosarcoma, which has true vascular channels containing erythrocytes sheathed by cells with mitotic activity and cytological atypia, is the foremost condition for PASH dif- ferential diagnosis in histological evaluation. ${ }^{9}$ PASH specific distinctive features comprise the anastomosing slit-like spaces coated with spindle cells mimicking vascular channels, with a none-tolow mitotic count, and without nuclear atypia or cytological pleomorphism. ${ }^{4,5}$ Immunohistochemical stains are essential in challenging situations. In general, PASH and angiosarcoma stain positively for CD34. On the other hand, the cellular adhesion marker CD31, which is mostly restricted to endothelial neoplasms, is positive in angiosarcomas and negative in PASH. ${ }^{2,4,8}$

In regard to treatment, the optimal strategies remain controversial. Several factors, such as tumor size, patient's age, intensity of symptoms and cosmetic results, must be balanced. Moreover, it should be considered that even though PASH is a benign neoplasm, malignant tumors may coexist with PASH lesions, therefore the histologic analysis accomplished by core needle biopsy could be insufficient to allow an accurate diagnosis, particularly in cases of 
mass-forming PASH. ${ }^{6}$ Therefore, according to literature, treatment is usually not necessary for incidental and non-suspicious focal lesions. With regard to nodular forms of PASH, wide excision remains the cornerstone of management. ${ }^{1,4,10}$

Highly variable recurrence rates following excision have been reported, ranging from $0 \%$ to $29 \%$, largely attributed to incomplete excision or presence of unknown multifocal lesions. ${ }^{6,11}$

In our case, surgical excision was performed, with successful clinical and cosmetic results and no recurrence at 3-year follow-up.

In conclusion, PASH is a benign proliferative breast disease, extremely uncommon in adolescent patients, especially in premenarchal girls. Regarding the vast spectrum of expressions of the disease, both radiological and clinical, differential diagnosis is challenging. Therefore, biopsy is necessary to establish a precise diagnosis. Several factors influence the clinical management, such as tumoral histology and size, expected cosmetic results, patient's age and preference. This case report highlights a rare clinical scenario made increasingly complex by the age of the patient and the size of the tumor.

\section{Source of Finance}

During this study, no financial or spiritual support was received neither from any pharmaceutical company that has a direct connection with the research subject, nor from a company that provides or produces medical instruments and materials which may negatively affect the evaluation process of this study.

\section{Conflict of Interest}

No conflicts of interest between the authors and / or family members of the scientific and medical committee members or members of the potential conflicts of interest, counseling, expertise, working conditions, share holding and similar situations in any firm.

\section{Authorship Contributions}

Idea/Concept: Eliana Teixeira, Lurdes Ramalho; Design: Eliana Teixeira, Daniela Pereira; Control/Supervision: Cristiana Gonçalves, Lurdes Ramalho, Carlos Firmino; Data Collection and/or Processing: Lurdes Ramalho, Carlos Firmino, Carlos Montenegro; Analysis and/or Interpretation: Eliana Teixeira, Cristiana Gonçalves, Lurdes Ramalho; Literature Review: Daniela Pereira, Eliana Teixeira; Writing the Article: Eliana Teixeira, Cristiana Gonçalves; Critical Review: Cristiana Gonçalves, Lurdes Ramalho; Materials: Carlos Montenegro, Lurdes Ramalho.

\section{REFERENCES}

1. Testori A, Alloisio M, Errico V, Bottoni E, Voulaz E, Fernandez B, et al. Pseudoangiomatous stromal hyperplasia- a benign and rare tumor of the breast in an adolescent: a case report. J Med Case Rep. 2017;11(1):284. [Crossref] [PubMed] [PMC]

2. Baker M, Chen H, Latchaw L, Memoli V, Ornvold K. Pseudoangiomatous stromal hyperplasia of the breast in a 10-year-old girl. J Pediatr Surg. 2011;46(8):e27-31.[Crossref] [PubMed]

3. Abdelrahman T, Young P, Kozyar O, Davies E, Dojcinov S, Mansel RE. Giant pseudoangiomatous stromal hyperplasia presenting in the breast of a prepubertal child. BMJ Case Rep. 2015;2015:bcr2014206797.[Crossref] [PubMed] [PMC]

4. Raj SD, Sahani VG, Adrada BE, Scoggins ME, Albarracin CT, Woodtichartpreecha $\mathrm{P}$, et al. pseudoangiomatous stromal hyperplasia of the breast: multimodality review with pathologic correlation. Curr Probl Diagn Radiol. 2017;46(2):130-5.[Crossref] [PubMed]

5. Yoon KH, Koo B, Lee KB, Lee H, Lee J, Kim JY, et al. Optimal treatment of pseudoangiomatous stromal hyperplasia of the breast. Asian J Surg. 2020;43(7):735-41.[Crossref] [PubMed]

6. Kurt E, Turanlı S, Markoç F, Berberoğlu U. How to manage pseudoangiomatous stromal hyperplasia: our clinical experience. Turk J Med Sci. 2017;47(5):1410-15.[Crossref] [PubMed]

7. Alikhassi A, Ensani F, Omranipour R, Abdollahi A. Bilateral simultaneous pseudoangiomatous stromal hyperplasia of the breasts and axillae: imaging findings with pathological and clinical correlation. Case Rep Radiol. 2016;2016: 9084820.[Crossref] [PubMed] [PMC]

8. Bowman E, Oprea G, Okoli J, Gundry K, Rizzo
M, Gabram-Mendola S, et al. Pseudoangiomatous stromal hyperplasia (PASH) of the breast: a series of 24 patients. Breast $\mathrm{J}$. 2012;18(3):242-7. .[Crossref] [PubMed] [PMC]

9. Dai H, Connor C, Cui W, Gatewood J, Fan F. Bilateral diffuse tumorous pseudoangiomatous stromal hyperplasia: a case of bilateral mastectomy in a 29-year-old woman. Case Rep Pathol. 2014;2014:250608.[Crossref] [PubMed] [PMC]

10. Kutlutürk K, Usta S, Ünal B, Karadağ N, Akatı AN. Pseudoangiomatous stromal hyperplasia of the breast presenting as a giant breast tumor: a case report. J Breast Health. 2015;11(1):39-41. .[Crossref] [PubMed] [PMC]

11. Tsuda B, Kumaki N, Ishida R, Sakaeda E, Ishii $\mathrm{S}$, Mizuno M, et al. Rare finding of bilateral pseudoangiomatous stromal hyperplasia of the breast: a case report. Tokai J Exp Clin Med. 2019;44(4):73-9.[PubMed] 